\title{
LA MÚSICA Y LAS TROBAIRITZ. EL TESTIMONIO DE LA COMTESSA DE DIA ${ }^{1}$
}

\author{
MUSIC AND TROBAIRITZ. THE TESTIMONY OF COMTESSA DE DIA
}

Antonia Víñez Sánchez y Juan Sáez Durán

Universidad de Cádiz

\section{Resumen:}

La primera estrofa de la canso A chantar m'er de so q'ieu no volria de La Comtessa de Dia, único texto con partitura que se conserva del grupo de las trobairitz, se ha transmitido en el folio $204 r-v^{o}$ del ms. W que analizamos como testimonio de la relación poesía/música junto al material iconográfico conservado de la misma -cinco miniaturas- que nos ofrecen los cuatro grandes cancioneros de la poesía trovadoresca del s. XIII (A, I, K y H).

\section{Palabras claves:}

Trobairitz, Música, Miniaturas, Simbología.

\section{Abstract:}

The first stanza of the canso A chantar m'er de so q'ieu no volria by La Contessa de Dia, the only extant Trobairitz text with a score, has been preserved in the folio $204 \mathrm{r}-\mathrm{v}^{\mathrm{o}}$ of the $\mathrm{W}$ manuscript which is here analysed as proof of the relationship between poetry and music, together with the iconographic material five miniatures - that accompanies it in the four great songbooks of troubadour poetry of the 13 th century (A, I, K and $\mathrm{H}$ ).

\section{KEY WORD:}

Trobairitz, Music, Miniatures, Symbolism.

1 Este trabajo forma parte del Grupo de Investigación HUM725 de la Junta de Andalucía y del Proyecto de investigación AGAUR, ref. 2014SGR51: "Pragmàtica de la literatura a l'Edat Mitjana". 
La afirmación de Nicolas Bell de que “La música constituyó una parte primordial de la vida cultural a lo largo de la Edad Media" pone de manifiesto un hecho innegable. Ahora bien, la mayor parte de nuestro conocimiento de la vida musical en el Medievo procede de fuentes ligadas a la iglesia, por el poderoso control que ésta ejercía sobre la cultura y la vida cotidiana. En cuanto a la tradición musical secular, que se apoya en la notación litúrgica, plantea cuestiones propias, como la determinación de su naturaleza sólo vocal -como sucedía con la música religiosa y la liturgia- o quizá también instrumental: "Había existido una larga tradición de poesía secular de carácter más culto cantada con música, tanto en latín como en lenguas vernáculas, pero era poco frecuente que la música se escribiera en manuscritos" y, de hecho, no es hasta avanzado el s. XIV cuando se hace habitual que se escribiera la notación para instrumentos (Bell, 2006: 5, 39-41). Marcello Schembri representa, en los últimos años, el máximo exponente del rechazo a la práctica de ejecución actual "agli antipodi della scientificità", dando como resultado lo que denomina "un Medioevo putativo" (2008-20010: 397-399). Para el autor "maggiormente documentato e il canto solo" y declara "la necessità, se si vuol parlare di filología, del pieno e rigoroso rispetto della tradizione manoscrita, che equivale semplicemente a cantare la melodia così com'è, senz trasfigurazioni, senza ingerenze strumentali, con voce naturale e, magari, con corretta e distinta pronuncia" (2005: 286-287) ${ }^{1}$.

El panorama heterogéneo de las múltiples modalidades de la interpretación medieval que con tanta minuciosidad y plasticidad nos describe Paul Zumthor, implica cuanto menos la aproximación a aspectos como la oralidad ( $\mathrm{u}$ "oralidades") y la formulación escrita de la misma ${ }^{2}$, sin olvidar el papel de la memoria en ambos registros y el

1 Con una actitud menos radical, pero en la línea de lo expuesto, Bell afirma que "las representaciones de instrumentos contribuyen en gran medida a llenar algunas de las lagunas que nos ha dejado la escasez de música instrumental notada, pero la información que nos proporcion exige una enorme cautela por parte del erudito moderno", ya que los miniaturistas, más que imágenes reales, parecían más interesados en reproducir instrumentos según estilos y géneros de iluminación y teniendo presente el patrocinio del ms., ob. cit., pp. 49 y 57.

2 Nos referimos a su monumental trabajo La letra y la voz. De la "literatura" medieval, Madrid, Cátedra, 1989. Para Zumthor el copista recibe auditivamente el texto, bajo dictado, p. 123. Christelle Chaillou describe una situación similar en la que en el proceso de transmisión del repertorio, llega a ó́dos del escriba, en “La poésie lyrique des troubadours. Musique, poésie, contexte, Annales de Vendée 2009, p. 3. Siguen la estela de Dietmar Rieger, que muestra los indicios de cómo el canto trovadoresco era no solo oído, sino también leído, como "une possibilité de réception complémentaire", basándose en las estructuras complejas y técnicamente refinadas de la composición, que el auditorio debía comprender intelectualmente, en "Audition et lectura dans le domaine de la poésie troubadouresque. Quelques réflexions sur la philologie provençale de demain", Revue des langues romanes, 87 (1983) pp. 69-85, incluida en el volumen Chanter et dire. Études sur la littérature du Moyen Âge, París, Honore Champion, 1997, pp. 31-44. La cita de la p. 44. El análisis de la tipología de "oralidades" en Zumthor p. 21 complicado asunto del proceso y técnicas de composición, aún sin resolver³ así como el vigente debate sobre trovador versus juglar ${ }^{4}$.

La música trovadoresca es monódica y sólo aparece anotada la primera estrofa, de lo que se deduce la repetición de la melodía en el resto del poema ${ }^{5}$. Son varias las formas de representación de la música por escrito en el Medievo, pero lo usual es, como en la música actual, la notación por neumas: signos indicadores del movimiento melódico, pero que, frente a la notación actual, no indicaban el ritmo, sino sólo el tono de las notas, lo que deriva en un grave problema técnico y filológico ${ }^{6}$, que Gérard Le Vot resume así: "Pour pallier l'indétermination rythmique de la notation des manuscrits, les musicologues eurent d'abord recours à des solutions mensuralistes", de este modo Hugo Riemann, Pierre Aubry, Jean Beck, Hans Spanke y Friedrich Gennrich nos ofrecen soluciones diversas, como la teoría modal mezclada en ocasiones con modos rítmicos de la notación polifónica, cuando no se plantea un enfoque completamente distinto basado en la declamación, con resultados completamente subjetivos, lo que deriva en una "diversité rythmique surprenante" (1982: 205-206). Antoni Rossell, propone que “La solución al ritmo monódico hay que buscarla en la misma monodia, en la paleografía y en su interpretación semiológica a partir de estudios de semiología comparada con la notación gregoriana, y en la prosodia del texto" (1996: 78), teniendo muy presente la monodia religiosa y su estrecha vinculación con el origen de la poesía trovadoresca, presente ya en la raíz misma de los términos "trobar"/“trobador", derivados de los latinos "tropare"|"tropatore", que nos remiten al "tropus" o composiciones con melodía del canto litúrgico extendidas en el siglo XI (M. de Riquer, I, 1983: 20). A esto hay que añadir que no siempre las versiones de una misma melodía coinciden en todos los manuscritos que la transmiten y que un mismo texto puede presentar melodías distintas, lo que plantea la debatida cuestión del papel de la oralidad en la trasmisión de la poesía trovadoresca. Así, para Olivier Cullin y Christelle Chailou “l'écrit musical manuscrit -trace d'une performance orale qui lui est antérieure- conserve l'essence

3 Para Walter J. Ong el poeta escribe imaginándose su declamación ante el público, interiorizando el sonido, en Orality and Literacy. The Technologizing of the Word, London-New York, Routlege, 2002, pp. 99-101. Para Zumthor, era requisito el uso de tablillas de cera antes de pasar a pergamino cualquier escrito, constituyendo el dictare "lo que percibimos como origen del texto", p. 120. 4 Utilizamos la expresión del trabajo de Gema Vallín que muestra una síntesis del agudo
problema: "Trovador versus juglar: conclusiones de la crítica y documentos", en Toro Pascua, M. I. (ed.), Actas del III Congreso de la Asociación Hispánica de Literatura Medieval, Tomo II, Salamanca, Gráficas Varona, 1994, pp. 1115-1120.

5 Chaillou, en cambio, en el terreno de la hipótesis y sin fundamento real alguno, cree que según la dinámica mentalidad medieval, la melodía podría admitir variaciones en cada estrofa, art. cit., p. 6.

6 "A discapito di tutti gli altri problema, quello del ritmo ha polarizzato da sempre l'interesse e la cura degli studiosi", afirma M. Schembri, "Interpretare i trovatori. Una quaestio da aprire", en Castano, R; Guida, S; Latella, F. (eds.), Scène, évolution, sort de la langue et de la littérature d'oc. Actes
septième Congrés International de l'Association Internationale d'Études Occitanes, Viella, 2003, p. 641. 
de la composition et permet de comprendre comment la mémoire s'exerce dans un contexte de tradition orale, quels sont les modes particuliers de sa transmission et de sa conservation, quels rapports ambigús entretiennent entre eux oralité et écriture" (2006: 144).

Situándonos en la poesía trovadoresca, "la lírica de los trovadores debe ser abordada en su doble realidad poética y musical, partiendo de la "unidad" texto/ música, sin que una o la otra puedan tratarse independientemente", como señala A. Rossell (1996: 62). Así, se entiende la obra como fusión de so (elemento musical), motz (elemento propiamente textual) y razo (tema), refiriéndose el primero a la estructura formal del texto en su conjunto, lo que deriva en el problema de la relación música/ versificación (Cerullo, 2009: 155-159)7. Los textos poéticos corteses que han sobrevivido musicalmente anotados son testimonios de la existencia del vínculo entre la poesía y la voz, de hecho: "nadie pone en duda, a pesar del escaso número de las melodías subsistentes, la oralidad de la poesía de los trovadores, troveros y Minnesänger, al menos, en lo que se refiere a su comunicación" (Zumthor, 1989: 42, 62). Esa realidad dual se materializa en cifras significativas que requieren descodificación. En lo que concierne a la poesía occitana, principalmente cuatro de los 95 manuscritos que trasmiten casi 2600 poesías líricas, incluyen las 264 melodías conservadas actualmente ${ }^{8}$. Oscilan cronológicamente entre los siglos XIII y XIV. De mediados del XIII es el ms. X, también denominado Chansonnier de Saint-Germain-des Pres, procedente del norte de Francia; el ms. R, occitano, es del s. XIV, como el ms. G, datado a principios del s. XIV (Aubrey, 2000: 34-49) ${ }^{9}$ y, por último, el ms. W, de finales del s. XIII, también llamado Manuscrit $d u R o i^{10}$, procedente de la misma zona que $\mathrm{X}$, cuya importancia radica en

$7 \quad$ En la Doctrina de compondre dictats se especifica acerca del sirventés: “e potz seguir las rimas The Razos de trovar of Raimon Vidal and associates texts, London, Oxford University Press, 1972, p. 96

8 Frente a las más de dos mil melodías que conocemos de los trouvères, cf. Rossell, A., “Antología musical", en Alvar, C., Poesía de trovadores, trouvères y minnesinger, Madrid, Alianza Editorial, 1982, p. 377. Para Michel Zink el interés por la conservación de la melodía en los cancioneros de la escuela de los trouvères contrasta con la pauta de insertar noticias biográficas (Vidas) o textuales (Razos) en los cancioneros de la poesía trovadoresca, representando dos polos opuestos en la recepción poética, "car la mélodie invite l'utilisateur du manuscrit à abandonner son rôle passif de simple récepteu du poème pour le rôle actif de l'interprète", en Zink, M.,"Musique et subjectivité. Le passage de la chanson d'amour à la poésie personnelle au XIIIe siècle", Cahiers de Civilisation Médiévale, vol. 25, n 99-100 (1982), p. 226.

9 El paréntesis de tiempo desde que la lírica occitana florece a la fijación en estos cancioneros da pie a pensar que la transmisión haya podido sufrir modificaciones tanto por el copista como por lo intérpretes, trovadores o juglares.

En cuanto a la localización de los manuscritos, $G$ se halla en la Biblioteca Ambrosiana de Milán (R71 superiore); R, Xy W en la Bibliotèque Nationale de France (fr. 22543, fr. 20050, fr. 844, respectivamente). 10 El códice fr. 844 de la BNF contiene 60 poesías del rey Thibaut de Navarra, de ahí su nombre, proporcionando 55 melodías de trovadores y 365 melodías de trouvères en 217 folios de pergamino con piezas añadidas en los espacios en blanco en los siglos XIV y XV. Está integrado por el cancionero francés M, El cancionero francés t (f. 13 y 59-77) y el occitano W (f. 188-204 y 212-213). Para un el tema que nos ocupa en que contiene el único texto con anotación musical de una trobairitz. Porcentualmente no es de extrañar la sorprendente cifra, teniendo en cuenta que de 360 trovadores sólo una veintena son mujeres, es decir, algo más del 5\%, cuyo corpus está constituido por 46 composiciones conservadas ${ }^{11}$, cifra que no llega ni al 2\% del global de textos poéticos. Sabemos el nombre de las autoras por las rúbricas de los cancioneros o porque son nombradas en los géneros dialogados, pero en trece de ellos la trobairitz aparece sólo designada como "domna"12, lo que prueba el exilio poético de que fueron objeto en su época, traducido posteriormente a un silencio bibliográfico, con alguna excepción, hasta la aparición del emblemático libro The Women Troubadours de Meg Bogin en 1976 ${ }^{13}$

La primera estrofa de la canso A chantar m'er de so q'ieu no volria de la Comtessa de $\mathrm{Dia}^{14}$, único texto con partitura del grupo de las trobairitz, se ha transmitido en el folio $204 \mathrm{r}-\mathrm{v}^{\circ}$ del $\mathrm{ms}$. W. El texto de la composición nos ha llegado a través de catorce manuscritos diferentes ${ }^{15}$. Se trata de una cansó, de cinco coblas singulars y una tornada de dos versos, cuyo esquema es (Frank, 1966: 25.2): a10' a10' a10' a10' b10 a10' b10.

acercamiento al mismo, cf. Dickinson Haines, J., The Musicography of the "Manuscrit du Roi", University of Toronto, 1998. Tambien Spanke, H., "Der Chansonnier du Roi", Romanische Forschunge, 57, 1 (1943) pp. 38-104. El cancionero puede consultarse en la BNF, en red: [http://archivesetmanuscrits.bnf.fr/ ead.html?id=FRBNFEAD000051092

11 Editadas por Angelica Rieger, Trobairiz. Der Beitrag der Frau in der altokzitanischen höfischen Lyrik. Edition des Gesamtkorpus, Tübingen, Max Niemeyer Verlag, 1991.

12 Hay un total de 24 canciones anónimas. Cf. Riquer, I. de, “Tota dona val mays can letr'apren: La trobairitz", en Carabí, A.; Segarra, M. (eds.), Mujeres y Literatura, Barcelona, PPU, 1993, pp. 23-25.

13 Entre las excepciones cuentan Oskar Schultz-Gora, Die provenzalischen Dichterinnen, Leipzig, G. Fock, 1988 y, sobre todo, la importante recopilación de Jules Véran, Les poétesses provençales du moyen âge et de nos jours, París, Librairie Aristide Quillet, 1946. Pierre Bec edita una antologia en 1995 unièndose a loque denomina "le phenomenedes femmes troubadours" dudando igualmente de la autoría en aquellas tenzós donde no aparece explícitamente e nombre de la interlocutora femenina, cf. Chants d'amour des femmes troubadours. Trobairit nombre de la interlocutora femenina, ct. Chants d'amour des femmes troubadours. Trobairitz Riquer, I. de "Las trobairitz", en Zavala, I. M. (coord.), Breve historia feminista de la literatura española (en lengua catalana, gallega y vasca), vol. VI, Barcelona, Anthropos, 2000, pp. 27-39.

14 Seguimos la edición de A. Rieger, ob. cit., 1991: nº 35, pp. 592-599. Ha sido editada en muchas ocasiones. En 1917 G. Kussler-Ratyé edita sus cuatro poesías además de una tenzó atribuida a Raimbaut d'Aurenga junto a la trobairitz, si bien en ningún lugar justifica esta inclusión, en "Le chansons de la comtesse Beatrix de Die", Archivum Romanicum, l, pp. 161-182. El asunto de su autoria es tan confuso como la propia biografia de la trobairitz. M. de Riquer reproduce las cuatro composiciones de clara atribución sin incluir la dudosa tenzó, fingida para el editor, que presenta una gran similitud con una de las composiciones de la condesa. Debemos senalar, no obstante, que en otro lugar se refiere a "las cinco poesías de la comtessa de Dia", cf. Riquer, M. de, Los trovadores.T. I, ob. cit., pp. 791-793.

15 Son los manuscritos A, B, C, D, G, I, K, L, M, N, R, W, a y b. El ms. M la adscribe a "una donna de Tolosa", cf. Riquer, idem, p. 800. A. Rieger, ob. cit., p. 592 
La melodía ha sido editada asimismo en numerosas ocasiones ${ }^{16}$, así en las últimas décadas por Erhardt Lommatzsch (1957), Friedrich Gennrich (1958) y Pierre Bec $(1979)^{17}$. La cobla de La Comtessa de Dia se inserta en la columna derecha en la zona inferior del folio y continúa en la columna izquierda del folio vuelto en la zona superior del mismo. La vocal de inicio, de gran tamaño, como es usual en todo el cancionero, está adornada en oro, tinta azul y roja, con filigranas en su interior. A finales del s. XI, se había convertido en costumbre trazar una línea en el pergamino para asegurar la correcta alineación de los neumas. El diagrama de cuatro líneas, como vemos en este caso, se implanta en todos los libros de música desde el s. XIII, con neumas "en nota cuadrada", tomados de la paleografía gregoriana (Rossell, 196: 75) ${ }^{18}$, empleado ya en toda Europa occidental a finales de siglo (Bell, 2006: 27-28). La tinta de la partitura, en rojo, contrata con el texto y las notas en negro. La presentación de la cobla no respeta la división línea/verso, ya que "L'unité du vers est peut-être moins mise en valeur", si bien el signo gráfico del punto divide en versos las estrofas casi sistemáticamente en todo el manuscrito $\mathrm{W}$, así como las barras verticales en finos trazos al final de cada uno de los versos cuya "fonction de limite et de repos dans le discours chanté ne peut alors être mise en doute", como señala Gérard Le Vot (1982: 208-209). Con relación al cancionero, "i testimoni di area francese sono frammentari (di solito inseriti in raccolte di liriche di trovieri) e fortemente imbastarditi dal punto di vista linguistico, se non addirittura francesizzati", como afirma Maria Luisa Meneghetti (1984: 198), característica que hallamos en la cobla de La Comtessa. M. de Riquer sitúa a la trobairitz a finales del s. XII o principios del XIII, ya que lo que conocemos de la misma se basa fundamentalmente en los indicios que se derivan de su escueta Vida, que ha dado lugar a múltiples especulaciones, también a rasgos intertextuales, estudiados sobre todo por W. T. Pattison (1952). En cuanto a la Vida, el texto dice: “La comtessa de Dia si fo moiller d'En Guillem de Peitieus, bella domna e bona. Et enamoret se d'En Rambaut d'Aurenga, e fez de lui mantas bonas cansos" ${ }^{\prime 19}$.

16 Remitimos a la bibliografía que ofrecen M. de Riquer y A. Rieger. Ibídem.

17 Este último lleva a cabo la transcripción musical de la cobla con la segmentación en versos y sílabas, alejándose de la interpretación modal con una transcripción "le plus «neutre» posible" desde el punto de vista rítmico que, no obstante, basa en el método de H. Van der Werf, autor de la tendencia "subjetivista". Cf. López Elum, P., Interpretando la música medieval del siglo XIII. Las Cantigas «Not-so-precisely Measured» Music of the Middle Ages", Performance Practice Review, vol. 1, no 1 «Not-so-precisely Measured» Music of the Middle Ages", Performance Practice Review, vol. 1, n⿳ Rhythmus in den Chansons de Trouvères", Die Musikforschung, 20 (1967), pp. 122-144. La versión discográfica más difundida de la cansó es la de HESPERRION XXI-JordiI Savall, Cansos de trobairitz, c. 1200, Virgin Edition, London, 1996.

18 Se distingue el punctum y la virga para los neumas de una nota, pes y clivis para los de dos $\mathrm{y}$, finalmente, chacus, torculus y porrectus para los de tres.

19 "La condesa de Día fue esposa de Guilhem de Peitieu, hermosa y buena dama. Y se enamoró de Raimbaut d'Aurenga, y le dedicó muchas buenas canciones". El texto de Boutière, J; Schutz, A. Cluzel, I.-M., Biographies des troubadours, Paris, Nizet, 1973, p. 445 y su traducción en M. de Riquer
Barajando los datos que explicita la breve biografía, la primera hipótesis la identifica con Beatriz, hija de Guigues IV, casada con Guillermo I de Poitiers, conde de Valentinois, con posesiones en Die entre 1163 y 1189, fechas que coinciden con años de producción del trovador Raimbaut d'Aurenga ${ }^{20}$. Una segunda propuesta, sostenida por Pattison, identificaría a la trobairitz con Isoarda de Dia, casada con Raimon d'Agout antes de 1184 hija del conde de Dia, localizada en Aurenga y que muere entre 1212 y 1214. Quizá su amante pudo ser Raimbaut IV de Aurenga, posiblemente autor de tres composiciones, atribuidas a su tío-abuelo, el trovador Raimbaut d'Aurenga (Pattison, 1952: 29-30) ${ }^{21}$. La relación entre la trobairitz y el conocido trovador también se defiende con argumentos de intertextualidad, ya que la condesa pudo ser la contrincante literaria en la famosa tensó Amics, en gran cossirier, que recuerda sin duda su cansó Estat ai en greu cosirier hecho que Pattison niega al sostener que se trata un debate fingido del trovador ${ }^{22}$.

Al primer testimonio de la naturaleza musical de las composiciones de las trobairitz la casi milagrosa presencia de la partitura de la cobla de La Comtessa de Dia en el cancionero $W$, debemos añadir una argumentación de naturaleza visual: la iconografía presente en cuatro grandes manuscritos del s. XIII, elaborados en la zona nororiental de Italia, en la región del Véneto (Rieger 1985: 386), con un interesante legado de retratos de trobairitz. Se trata de los cancioneros $\mathrm{A}, \mathrm{I}, \mathrm{K} \mathrm{y} \mathrm{H}^{23}$. A partir de la descripción de estas poetisas en las imágenes podemos anticipar su innegable faceta como intérpretes, ya que la poesía es canto y las miniaturas son referencias escénicas muy eficaces que, en una lectura integrada, dan relieve al propio texto (Poggi, 2000: 101-103). Ninguna trobairitz es representada con instrumento, ya que se trata de evitar al máximo la confusión

\footnotetext{
Vidas y retratos de trovadores. Textos y miniaturas del siglo XIII, Barcelona, Galaxia Gutemberg, 1995, p. 237, n.129.

El primer trabajo de conjunto sobre estas biografías lo debemos a C. Chabaneau, Les biographies des troubadours en langue provençale, Édouard Privat. Libraire-Éditeur, Toulouse, 1885. Puede verse también: Favati, G., Le biografie trovadoriche, Bolonia, Palmaverde, 1961 y Panvini, B., Le biografie provenzali: valore e attendibilitat, Florencia, Olschki, 1952.

20 Seguimos a M. de Riquer que resume la problemática, Los trovadores, ob. cit., II, pp. 791 793. Raimbaut es un trovador perfectamente localizado y uno de los más prolíficos, con 40 composiciones. Se le sabe vivo en 1147 y muere en 1173. Dedicó a su dama, Azalais de Porcairagues, doce composiciones con el senhal de Joglar y Bel joglar. La trobairitz le dedicó un planto a su muerte en 1173, único texto conservado de la autora. Estudio y edición del texto en Sakari, A., "Azalais de Porcairagues, le Joglar de Raimbaut d'Orange", Neuplilologische Mitteilungen. Bulletin de la Sociéte Néophilologique de Helsinki, 50 [reimpresión Amsterdam, 1968], pp. 23-43, 56-87 y 174-198. También del mismo: "À propos d'Azalais de Porcairagues", Mélanges de Philologie Romane dediés à Jean Boutière, I, Liège, 1971, pp. 517-528.

21 Algunas hipótesis más pueden verse en Riquer. Ibídem.

22 Las composiciones en M. de Riquer, Los trovadores, I, p. 452-454 y II, 798-799. La cansó de La Comtessa también en A. Rieger, ob. cit., 1991, pp. 600-604.

23 A (lat. 5232) y H (lat. 3207) se hallan en la Biblioteca Vaticana; I (fr. 854) y K (fr. 12473) en la Biblioteca Nacional de París. Solo en los cuatro manuscritos del s. XIII aparecen las miniaturas relacionadas con las Vidas y Razós, copiadas con tinta roja, claramente diferenciadas del corpus poético, M. de Riquer, Vidas, ob. cit., pp. XXVI-XXVII.
} 
con las joglairitz, de más baja categoría social ${ }^{24}$. Por un total de dieciséis miniaturas podemos conocer a ocho trobairitz, siete de ellas identificadas y una anómina. Pese a que hay bastante similitud entre los grandes cancioneros estudiados, cada uno presenta sus propios rasgos particulares y en todos, a excepción de $\mathrm{H}$, que muestra ocho miniaturas independientes de trobairit $\mathrm{z}^{25}$, la figura se inserta en el cuadro de una inicial o letra historiada con fondo dorado en la primera poesía. Es tópico señalar el escaso valor artístico de estas ilustraciones en $\mathrm{H}$, así como los problemas del códice, sobre todo en lo que concierne a la parte donde se ubican las trobairitz, (Krispin 1993: 231-242), última sección del cancionero (f. 43 al 57 vo), que se corresponde al séptimo cuaderno, donde se acusa el desorden y descuido en relación a las partes anteriores del manuscrito ${ }^{26}$. En esta sección, en el f. $49 v^{\circ}$, aparece representada La Comtessa de Dia con dos miniaturas, lo que justifica para Rieger (1985: 390) una posible laguna, ya que es inusual la duplicación de imágenes. Es, sin duda, la trobairitz más representada de los cancioneros, con cinco imágenes, apareciendo también en A (f. 167), I (f. 141) y K (f. $\left.126 v^{\circ}\right)^{27}$.

El estudio iconográfico proyecta luz sobre la performance de la poesía trovadoresca. La tarea del iluminador era independiente a la del copista, como se deduce de las notas marginales por las que éste último daba instrucciones acerca de las pinturas en el cancionero A. Así sucede con La Comtessa de Dia, cuya nota marginal indica que ha de dibujar "vna dona que cante", hecho que fundamenta más allá de propia iconografía la hipótesis de las trobairitz como intérpretes de sus canciones. De hecho, es el códice más suntuoso en los dibujos frente a la austera y repetitiva ejecución de los demás, que parecen seguir un esquema prefabricado de las miniaturas con alguna variación cromática (A. Rieger, 1985: 387). Las miniaturas han de observarse, pues, no solo como mero retrato arquetípico, sino como expresión de la voz y de la puesta en escena que se manifiesta por medio de un específico -y simbólico- código gestual. Las Vidas y Razós complementan una valiosa información acerca de la actividad poética de las trobairitz, precisando el "buen trovar", como en el caso de Azalais de Porcairagues, Lombarda,

24 Para el tema de las "joglairitz", puede verse Aguilera, D., Femmes poètes du Moyen-Âge. Les Trobairitz, Paris, L'Harmattan, 2012, pp. 97 y ss.

25 El cancionero H, del siglo XIII, es insólito por esta razón. Para un acercamiento al mismo, véase Careri, M., Il canzoniere provenzale $H$ (Vat. Lat. 3207). Struttura, contenuto e fonti, Modena, Mucchi Editore, 1990.

Una explicación de este hecho es que pudo haber sido haber sido realizado por o para una mujer, como indica A. Rieger, A., "Ins e.l cor port, dona, vostra faisso. Image et imaginaire de la femme à (1985), p. 390. Además, dos tercios de las poesías femeninas que transmite son unica.

26 Las miniaturas en $\mathrm{H}$ siguen al texto ya que a veces el color invade a la escritura. Aparecen, además, Tibors, una trobairitz anónima, Almuc de Castelnau, Iseut de Capio, Maria de Ventadorn y Lombarda, ésta última en mejor estado de conservación y diferente tipología de colores, por lo que pudo ser obra de una segunda mano, cf. CARERI, p. 43.

27 Para el resto de miniaturas de trobairitz y su ubicación, cf. Jullian, 2007: 10.
Tibors y la propia Comtessa. (Riquer, 1995: 185, 267, 218 y 237) ${ }^{28}$. La singularidad del cancionero A también se manifiesta en la posición sentada con que "retrata" a La Comtesa, forma honorífica de presentación de personajes de superioridad jerárquica como en el caso de reyes y sabios (Garnier, 1982: 113). En el resto de imágenes, aparece de pie, girada levemente con cuerpo, cabeza, dirigiendo la mirada hacia un auditorio imaginario a la izquierda en todos excepto en $\mathrm{I}^{29}$, en el que lo hace a la derecha, inclinando la mirada hacia abajo en señal de abatimiento, con la mano menos alzada que en el resto de representaciones y expresando un estado anímico de tristeza -“Le personnage incline la tête lorsque pèse sur lui un poids physique ou moral", indica F. Garnier (1982: 181).- por lo que el miniaturista pudo tener presente la temática de sus cansós $^{30}$, ya que el cancionero traslada tres de las cuatro composiciones seguras de la trobairitz. Así, por ejemplo, en A chantar, expresa estos matices significativvos con extrema sinceridad poética: "c'atressi-m sui enganad'e trahia" (I, v. 6).

El alto nivel social de estas damas (domnas) se expresa por medio del código simbólico de la vestimenta. La Comtessa es representada con largos vestidos de colores intensos y adornos dorados, además de con manto forrado de armiño, como puede apreciarse en tres imágenes -I, $\mathrm{K}$ y H1${ }^{31}$, , prenda que categoriza socialmente al personaje como perteneciente a la alta aristocracia, al ser un artículo de lujo y ostentación (Guerrero Lovillo, 1949: 109-111). En A, aparece con vestido de mangas intercambiables, de distinto color siguiendo la moda del siglo XIII (Jullian, 2007: 5). En relación a los colores de la vestimenta, La Comtessa presenta una gran variedad, dominando el rojo, color de los mantos en I y K y del vestido de H2. También vemos el verde (I), el rosa (A, K) y el azul con adornos dorados (H1) ${ }^{32}$. Los colores significan y deben interpretarse en función del código simbólico (Lucca, 2005: 323-325). Así, el rojo simboliza la "pasión y exaltación en grado máximo", para J. E. Cirlot (1970: 11) como representante tópico del fuego amoroso tan presente en la retórica de la fin'amors, pero también representa la

28 El señalado carácter tópico del género y su incuestionable homogeneidad no excluye el hecho de que se establecen particularidades en la información que selecciona este material biográfico. Si todas se indica la procedencia geográfica, solo en cuatro de ellas, por ejemplo, se destaca su nivel de instrucción "enseingnada" en el caso de Azalais, Lombarda y Tibors, y "mou enseingnada" en el de Castelloza. La Vida de ésta última en M. de Riquer, Vidos, ob. cit., p. 176.

29 Las imágenes de las miniaturas en Riquer, idem, pp. 236 y 238-239.

30 Pudo existir, afirma Schembri, un propósito deliberado de traducir a imagen los aspectos de la Vida de Giraut de Bornelh en los tres cancioneros vénetos A, K e I, tal como planteamos aquí el caso de La Comtessa de Dia. Cf. "Una lettura”, art. cit., pp. 404-405.

31 Distinguimos las dos miniaturas de $\mathrm{H}$ con el indicador numérico. $\mathrm{H} 1$ es la primera dispuesta en el folio $49 \mathrm{v}^{\circ}$.

32 El oro es color apoteósico, como lo define Marie H. Moya en relación a los logros caballerescos y corteses de Lancelot, como símbolo benéfico que acompaña al héroe en combates violentos, pero también en momentos de intensidad amorosa, en "Les couleurs dans la structure narrative du Lancelot", Les couleurs au Moyen Âge, Publications du CUERMA, Université de Provence, 1988, pp. $276-277$. 
belleza, "el eros libre y triunfante", para Jean Chevalier y Alain Gheerbrant (2007: 889). El rosa, rojo atenuado, simboliza los afectos, pero también la carne y la sensualidad, mientras que el verde, color de Venus, se relaciona con la vegetación (Cirlot, 1988: 135-141 y 344)

En cuanto a la gestualidad del cuerpo, estudiada por la Kinésica, Fernando Poyatos (1994) distingue varias categorías de gestos, maneras y posturas. Los gestos se realizan con la intención de que alguien los vea, estableciendo un sistema comunicativo particular, sobre todo en una sociedad, como la medieval, fuertemente ritualizada (Díaz-Corralejo, 2004: 13-14). El comportamiento gestual de la iconografía de las trobairitz nos permite afirmar, en términos generales, que la finalidad de las imágenes es presentar un mensaje intencionado por la elección de gestos primarios, para nada casuales ni espontáneos (Miguélez Cavero, 2010: 8-9). Entre todos, destaca la mano alzada simbolizando el acto de cantar, si bien la boca permanecerá cerrada tan sólo esbozando una leve sonrisa, por la imposibilidad de parecer abierta según la filosofía de la mesura (modestia) de la gesticulatio, que condena esa expresión como diabólica (Schmitt, 1991: 130, 136). A excepción de las dos miniaturas de H, deterioradas en el rostro, podemos contemplar a La Comtessa de Dia con rostro discreto en las otras tres imágenes, que cumplen la norma estético-moral vigente. La Comtessa en A lleva el índice extendido o en punta, actitud frecuente de la representación regia, que expresa designación u orden. Las manos alzadas suelen estar abiertas, si bien las que sostienen objetos llevan puño cerrado. En cuanto a la otra mano, en K (derecha) e I (izquierda) reposa en el bolsillo, en actitud relajada, mientras que en $\mathrm{H}$ se posa en el pecho en ambas miniaturas ${ }^{33}$, simbolizando el carácter profundamente sentido de una situación, mientras que la mano en el regazo, ocupando parte del muslo, es indicativa de determinación y poder personal, tal como aparece en A (Garnier, 1982: 184-185). Como detalle excepcional, el miniaturista de $\mathrm{H} 2$ representa a La Comtessa sosteniendo con su mano derecha un halcón ${ }^{34}$. Como símbolo de dignificación, es innegable la evocación al mundo caballeresco y a la cetrería, si bien no podemos obviar el significado simbólico de los animales que, en el caso del halcón, como símbolo ascensional, hace referencia a la superioridad del personaje (Chevalier; Gheerbrant, 2007: 552). Se trata, en consecuencia, de un atributo no sólo de referencia, sino también de significación (Brea; Díaz; González, 1984: 75-100).

33 Para A. Rieger, art. cit., 1985, en H1 porta un bastón con la mano derecha, p. 391. El deterioro de la imagen impide apreciar ese detalle. Parece más bien que, como sucede en la segunda miniatura, la mano oprime el pecho, sin que podamos asegurarlo.

34 Maria de Ventadorn, la trobairitz anónima y -probablemente, aunque no se puede asegurar por el estado de la pintura- Almuc, portaban una rama en H. Son los elementos más creativos con que aparecen caracterizadas estas trobairitz en el conjunto.

Revista Internacional de Culturas y Literaturas, abril 2017 ISSN: $1885-362$
Los largos vestidos dejan entrever, no obstante, la parte inferior del cuerpo, con la presencia de los pies calzados asomando en algunas ocasiones, lo que indica actividad. A excepción de $\mathrm{K}$, donde están tapados, observamos los pies de La Comtessa en las demás imágenes. En A, sentada, los dirige al frente, en posición estable, como corresponde a un personaje sabio o virtuoso (Garnier, 1982: 232). Los vivos colores y la presencia de joyas y adornos (diademas) en el cabello, que podemos apreciar en I, K y H1, determinan la categorización social muy elevada del personaje. La imagen de La Comtessa en A representa el topos femenino de belleza, con el cabello rubio y recogido en un moño, símbolo de la mujer casada. En las demás imágenes aparece un tono más castaño, al igual que en el resto de trobairitz, lo que no contradecía al ideal de belleza que sí debía respetar estrictamente -como lo hacen las miniaturas- la blancura de la piel. Resalta la ostentosa e intencionadamente exagerada trenza de La Comtesa de Dia en la imagen de H2, moda estética que impera a lo largo del Medievo, indicativa igualmente del compromiso matrimonial frente al cabello suelto de las mujeres solteras (Bornay, 2010: 150). Nuevamente el miniaturista hubo de tener presente, como un eco, los "atrevimientos" poéticos de la trobairitz al caracterizarla de ese modo tan llamativo y sugerente. Pues la fuerza que se desprende de las imágenes es idéntica a la pasión de sus versos ${ }^{35}$.
35 Así entiende M. de Riquer la composición que nos ocupa, que define como “una joya de la poesía nobleza, su hermosura y su leal corazón para atraer al esquivo enamorado", Los trovadores, II, p. 800

Revista Internacional de Culturas y Literaturas, abril 2017 


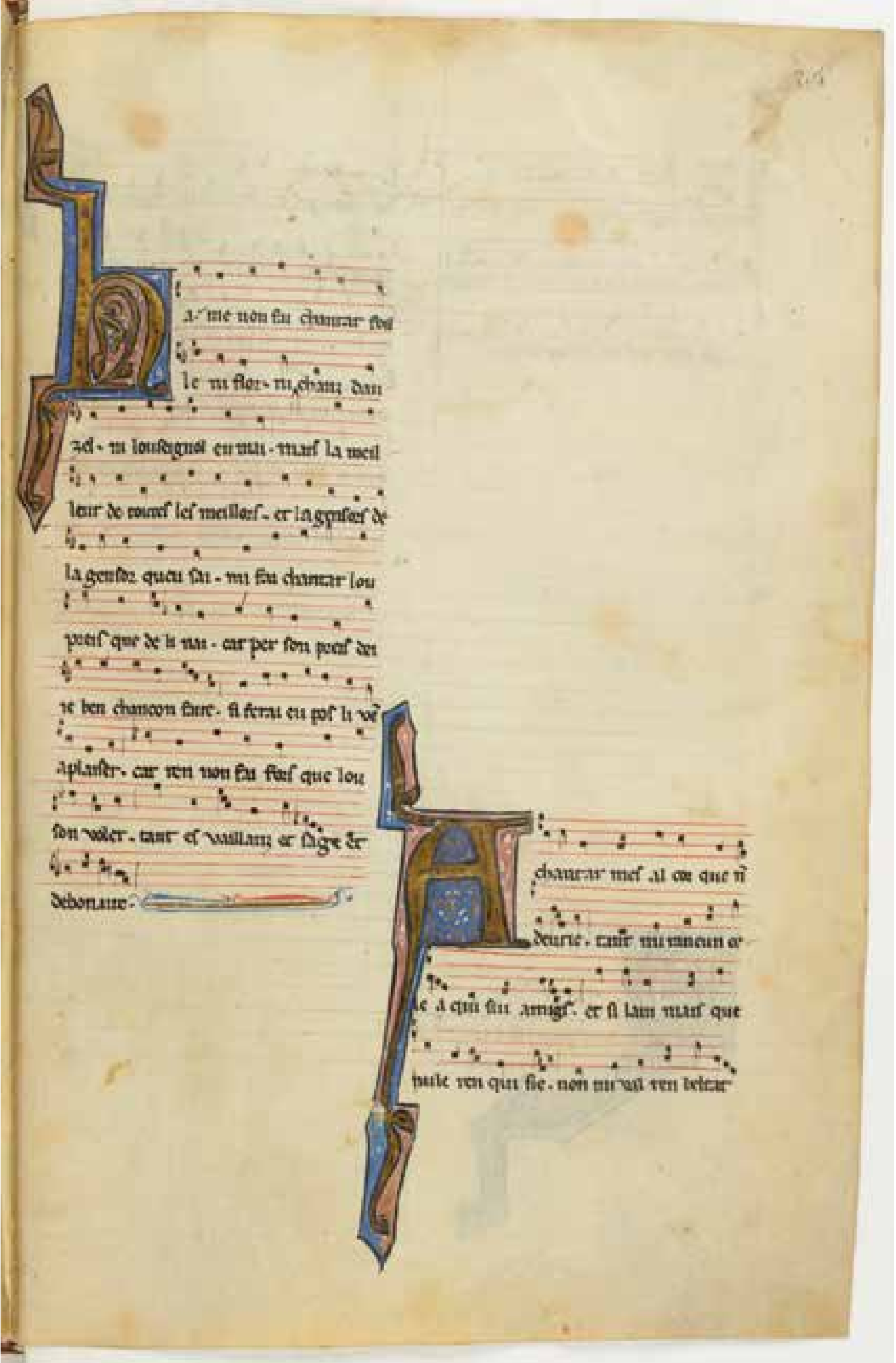

Fol. 204r del Cancionero W o Manuscrit du Roi (fr. 844). Source: Bibliothèque nationale de France.

\section{REFERENCIAS Y BIBLIOGRAFÍA}

Aguilera, D., Femmes poètes du Moyen-Âge. Les Trobairitz, Paris, L'Harmattan, 2012.

Aubrey, E., The Music of the Troubadours, Bloomington and Indianapolis, Indiana University Press, 2000.

Bec, P., Anthologie des troubadours, Paris, Union Générale d'Éditions,1979.

Bec, P., Chants d'amour des femmes troubadours. Trobairitz et «chansons de femme», Paris, Stock, 1995.

Bell, N., La música en los manuscritos medievales, Madrid, The British Library, AyN Ediciones, 2006.

Bogin, M., The Women Troubadours, London-New York, Paddington Press, 1976.

Bornay, E., La cabellera femenina. Un diálogo entre poesía y pintura, Madrid, Cátedra, 2010. Boutière, J.; Herman Schutz, A.; Cluzel, I.-M., Biographies des troubadours, Paris, Nizet, 1973.

Brea, M.; Díaz, J. M.; González, I., “Animales de referencia y animales de significación en la lírica gallego-portuguesa", Boletim de Filologia, 29 (1984), pp. 75-100.

Careri, M., Il canzoniere provenzale H (Vat. Lat. 3207). Struttura, contenuto e fonti, Modena, Mucchi Editore, 1990.

Cerullo, S., "Lirica e non-lirica nella poesia dei trovatori: intersezioni generiche e metrico-formali tra salut e canso", en Brugnoo, F; Gambino, F. (eds.), La lirica romanza del Medioevo. Storia, tradizioni, interpretazioni. Atti del VI convegno triennale della Società Italiana di Filologia Romanza, Padova, Unipress, 2009, pp. 155-174.

Chabaneau, C., Les biographies des troubadours en langue provençale, Édouard Privat. Libraire-Éditeur, Toulouse, 1885.

Chaillou, C., "La poésie lyrique des troubadours. Musique, poésie, contexte, Annales de Vendée, (2009), pp. 139-157.

Chevalier, J.; Gheerbrant, A., Diccionario de los símbolos, Barcelona, Herder, 2007.

Cirlot, J. E., "Vestida de rojo", La Vanguardia española (8 de julio, 1970), p. 11.

Cirlot, J. E., Diccionario de símbolos, Barcelona, Labor, 1988, $7^{\mathfrak{a}} \mathrm{ed}$.

Cullin, O.; Chaillou, C., "La mémoire et la musique au Moyen Âge", Cahiers de Civilisation Médiévale, 49 (2006), pp. 143-161.

Díaz-Corralejo, V., Los gestos en la literatura medieval, Madrid, Gredos, 2004.

Dickinson Haines, J., The Musicography of the "Manuscrit du Roi", Toronto, University of Toronto, 1998.

Favati, G., Le biografie trovadoriche, Bolonia, Palmaverde, 1961. 
Frank, I., Répértoire métrique de la poésie des troubadours, 2 vols., Paris, Honoré Champion, 1966.

Garnier, F., Le langage de l'image au Moyen Âge. Signification et symbolique, Paris, Le leopard d'or, 1982.

Gennrich, F., Der musikalische Nachlass der Troubadours, Darmstadt, 1958.

Guerrero Lovillo, J., Las cántigas. Estudio arqueológico de sus miniaturas, Madrid, CSIC, 1949.

Jullian, M., “Images des Trobairitz”, Clio. Femmes, Genre, Histoire, 25 (2007), pp. 2-13.

Kussler-Ratyé, G., "Les chansons de la comtesse Béatrix de Die”, Archivum Romanicum, I (1917), pp. 161-182.

Krispin, A., "La tradition manuscrite des trobairitz: le chansonnier H”, Atti del secondo Congresso Internazionale della Asociation International d'Études Occitannes, Torino, 1993, pp. 231-242.

Le Vot, G., "Notation, mesure et rythme dans la 'canso' troubadoresque", Cahiers de Civilisation Médiévale, vol. 25 (1982), pp. 205-217.

Lommatzsch, E., Leben und Lieder der provenzalischen Trobadors, I, Minnelieder, Berlín, 1957.

López Elum, P., Interpretando la música medieval del siglo XIII. Las Cantigas de Santa María, Valencia, Universitat de València, 2010

Lucca, P. di, "I trovatori e i colori", Medioevo Romanzo, vol. XXIX, fasc. 3 (2005), pp. 312-403.

Marshall, J. H., The Razos de trovar of Raimon Vidal and associates texts, London, Oxford University Press, 1972.

Meneghetti, M. L., Il publico dei trovatori. Ricezione e riuso dei testi lirici cortesi fino al XIV secolo, Modena, Mucchi Editore, 1984.

Miguélez Cavero, A., "Aportaciones al estudio de la gestualidad en la iconografía románica hispánica", Medievalista online, 8 (2010). <www2.fcsh.unl.pt/iem/ medievalista>

Moya, M. H., "Les couleurs dans la structure narrative du Lancelot", Les couleurs au Moyen Âge, Publications du CUERMA, Université de Provence, 1988, pp. 273-283.

Ong, W. J., Orality and Literacy. The Technologizing of the Word, London-New York, Routlege, 2002.

Panvini, B., Le biografie provenzali: valore e attendibilità, Florencia, Olschki, 1952.

Pattison, W. T., The life and Works of the troubadour Raimbaut d'Orange, Minneapolis, University of Minnesota Press, 1952.
Poggi, C., "Herralda de Hohenburg. Una artista magistral", Libres para ser. Mujeres creadoras de cultura en la Europa medieval, Madrid, Narcea, 2000, pp. 51-111.

Poyatos, F., La comunicación no verbal, 3 vols., Madrid, Istmo, 1994.

Rieger, D., "Audition et lectura dans le domaine dela poésie troubadouresque.Quelques réflexions sur la philologie provençale de demain", Revue des langues romanes, 87 (1983), pp. 69-85, incluida en el volumen Chanter et dire. Études sur la littérature du Moyen Âge, Paris, Honoré Champion, 1997, pp. 31-44.

Rieger, A., "Ins e.l cor port, dona, vostra faisso. Image et imaginaire de la femme à travers l'enluminure dans les chansonniers de troubadours", Cahiers de Civilisation Médiévale, 28, nº 4 (1985), pp. 385-415.

Rieger, A., Trobairiz. Der Beitrag der Frau in der altokzitanischen höfischen Lyrik. Edition des Gesamtkorpus, Tübingen, Max Niemeyer Verlag, 1991.

Riquer, I. de, "Tota dona val mays can letr'apren: Las trobairitz", en Carabí, A.; Segarra, M. (eds.), Mujeres y Literatura, Barcelona, PPU, 1993, pp. 19-38.

Riquer, I. de, "Las trobairitz", en Zavala, I. M. (coord.), Breve historia feminista de la literatura española (en lengua catalana, gallega y vasca), vol. VI, Barcelona, Anthropos, 2000, pp. 27-39.

Riquer, M. de, Los trovadores, Historia literaria y textos, 3 vols., Barcelona, Ariel, 1983.

Riquer, M. de, Vidas y retratos de trovadores. Textos y miniaturas del siglo XIII, Barcelona, Galaxia Gutenberg, 1995.

Rossell, A., "Antología musical", en Alvar, C., Poesía de trovadores, trouvères y minnesinger, Madrid, Alianza Editorial, 1982, pp. 375-405.

Rossell, A., “La música de los trovadores”, Cuadernos de Sección. Música 8 (1996), p. 53100.

Sakari, A., "Azalais de Porcairagues, le Joglar de Raimbaut d'Orange", Neuplilologische Mitteilungen. Bulletin de la Société Néophilologique de Helsinki, 50 [reimpresión Amsterdam, 1968], pp. 23-43, 56-87 y 174-198.

Sakari, A., “À propos d'Azalais de Porcairagues”, Mélanges de Philologie Romane dediés à Jean Boutière, I, Liège, 1971, pp. 517-528.

Schembri, M., "Interpretare i trovatori. Una quaestio da aprire”, en Castano, R; Guida S; Latella, F. (eds.), Scène, évolution, sort de la langue et de la littérature d'oc. Actes du septième Congrés International de l'Association Internationale d'Études Occitanes, Viella, 2003, pp. 639-649.

Schembri, M., "Arriva il Medioevo: si savi chi può! Breve e dolorosa vicenda della più clamorosa truffa culturale della storia della musica d'occidente", Nuova Rivista Musicale Italiana, 2 (2005), pp.283-294. 
Schembri, M., “Una lettura in chiave musicale del 'corpus' bio-iconografico dei trovatori (con riflessioni sull'odierna 'prassi esecutiva')", Rivista Italiana di Musicologia, 43-45 (2008-2010), pp. 395-437.

Schmitt, J.-C., "La moral de los gestos", en Feher, M.; Naddaff, R.; Tazi, N. (eds.), Fragmentos para una historia del cuerpo humano. Parte Segunda, Madrid, Taurus, 1991, pp. 129-146.

Schultz-Gora, O., Die provenzalischen Dichterinnen, Leipzig, G. Fock, 1988.

Spanke, H., "Der Chansonnier du Roi", Romanische Forschunge, 57, 1 (1943), pp. 38-104.

Vallín, G., “Trovador versus juglar: conclusiones de la crítica y documentos”, en Toro Pascua, M. I. (ed.), Actas del III Congreso de la Asociación Hispánica de Literatura Medieval, Tomo II, Salamanca, Gráficas Varona, 1994, pp. 1115-1120.

Van Der Werf, H., “The «Not-so-precisely Measured» Music of the Middle Ages", Performance Practice Review, vol. 1, no 1 (1988), pp. 42-60.

Van de Werf, H., "Deklamatorischer Rhythmus in den Chansons de Trouvères", Die Musikforschung, 20 (1967), pp. 122-144.

Véran, J., Les poétesses provençales du moyen âge et de nos jours, Paris, Librairie Aristide Quillet, 1946.

Zink, M.,"Musique et subjectivité. Le passage de la chanson d'amour à la poésie personnelle au XIIIe siècle", Cahiers de Civilisation Médiévale, vol. 25, no 99-100 (1982), pp. 225-232.

Zumthor, P., La letra y la voz. De la "literatura" medieval, Madrid, Cátedra, 1989.

Discografía: HESPÈRION XXI-JordiI Savall, Cansos de trobairitz, c. 1200, Virgin Edition, London, 1996. 